\title{
EVALUATING CORE INFLATION INDICATORS *
}

\author{
Carlos Robalo Marques ** \\ Pedro Duarte Neves ** \\ Luís Morais Sarmento **
}

\section{INTRODUCTION}

This study develops a set of properties that allow to assess, through adequate statistical tests, if a given indicator is an appropriate trend inflation measure. When analysing inflation developments, it is important to distinguish between permanent changes and transitory changes in the level of prices. The behaviour of the Consumer Price Index (CPI) is affected by a range of erratic or transitory factors, which do not reflect fundamental changes to the behaviour of inflation determinants. Take, for example, the extremely volatile behaviour of some foodstuff goods, more notably non-processed goods and services where price changes are concentrated in a single month or even situations where the level of prices of a given good is significantly adjusted. In any of these situations, it is quite difficult to identify the general trend of prices, as these one-off and temporary disturbances bring "noise" to inflation behaviour.

The conduct of monetary policy should not be affected by transitory disturbances in inflation. Since lags of monetary policy are long and a variable, it is crucial that the current general price trend is appropriately identified. For this purpose, a wide range of trend inflation indicators has been used by central banks to identify the "permanent" component of inflation. See, for instance, Cecchetti (1997), Coimbra and Neves (1997), Laflèche (1997), Bakhshi and Yates (1999), Álvarez and Matea (1999) and Wynne (1999). Despite the important

\footnotetext{
* The opinions of this paper represent the views of the authors, they are not necessarily those of the Banco de Portugal.

** Economic Research Department.
}

role this kind of indicator plays in analysing current price developments, there is no consensus in what concerns the properties such indicators should have.

This analysis is organised as follows ${ }^{(1)}$ : Section 2 presents the trend inflation indicators most widely used by the majority of central banks, and in particular by the Banco de Portugal. Section 3 proposes criteria for evaluating these indicators. Section 4 draws an assessment of several trend inflation indicators, making use of these criteria. Section 5 concludes.

\section{MOST WIDELY USED TREND INFLATION INDICATORS}

A fairly broad range of statistical techniques is available for obtaining trend inflation indicators. Wynne (1999) and Álvarez and Matea (1999) provide quite up-to-date syntheses of the main techniques used. In general, procedures can be grouped into two families. The first studies the cross-section distribution of year-on-year changes in prices. A broad range of indicators is calculated in this way, including "underlying inflation" and "limited influence" estimators such as the trimmed mean and the weighted median. The second set of trend inflation indicators results from exploring the time series characteristics of the

(1) This text is an abridged version of Marques, Neves and Sarmento (1999), "Evaluating Core Inflation Indicators", forthcoming in the Banco de Portugal Working Papers series. The reader may find in the paper a more comprehensive description of the technical procedures utilised. 
price index. This set includes, for instance, techniques of identification of the trend, seasonal and irregular components (through the application of fairly automatic process as in the case of X11-ARIMA, or TRAMO/SEATS), methods based on the Hodrick-Prescott and Kalman filters Bryan and Cecchetti (1993) and Cecchetti (1997) are an example of the latter kind of application or methods based on structural VAR models, as proposed in Quah and Vahey (1995) and applied to the Portuguese case in Dias and Pinheiro $(1995)^{(2)}$.

Central banks have made use of a relatively wide range of trend inflation indicators that are included in the first family presented above. This section draws a quick description of the most commonly indicators referred in the analyses of central banks.

Possibly the most broadly calculated indicator is the so-called "underlying inflation". This corresponds to the change of prices when excluding the classes of goods exhibiting a more volatile behaviour (i.e., non-processed food and energy). The higher volatility of these goods reflects wellknown factors: the low demand-price elasticity of most non-processed foodstuff goods explains that changes in supply conditions - many times determined by climatic factors - are almost fully translated into price changes; the wide oil price changes in the international markets, as well as the US dollar fluctuation and the changes in the taxation of oil products, account in turn for the volatility of energy prices.

Bryan and Cecchetti (1994) proposed "limited influence" estimators like the trimmed mean and the weighted median as means to obtain central location measures of price changes. This kind of indicators is obtained after excluding outliers in price changes, both for extreme increases as for reductions. The statistical explanation ${ }^{(3)}$ for using this kind of measure derives from the empirical evidence that the cross-section distribution of prices changes is strongly leptokurtical (i.e., it has fat tailes). Statistical evidence widely supports this characteristic of the cross-section distribution for year-on-year price changes of goods and services

(2) See Gartner and Wehinger (1998) for an application of this methodology to some European Union countries. included in the CPI (see for example Bryan and Cecchetti (1996), Coimbra and Neves (1997), Roger (1997) and Bakhshi and Yates (1999), respectively for the USA, Portugal, New Zealand and the United Kingdom).

Under these circumstances, the sample mean no longer exhibits the required statistical attributes, as it is very sensitive to outliers. In fact, the more leptokurtic the distribution, the more sensitive the sample mean is to outliers and, in principle, the greater is the percentage of observations to be excluded in the calculation of the trimmed mean.

Following the suggestion of Bryan and Cecchetti (1994), some central banks started to disclose "limited influence" estimators as indicators of trend inflation. This was the case of the Bank of England, the Bank of Australia and the Banco de Portugal.

The computation of the trimmed mean indicator raises, nevertheless, some issues: what should be the percentage of outliers that should be excluded $^{(4)}$, whether this percentage should be allowed to change in time or not, whether the highest and the lowest observations should be excluded by the same amount ${ }^{(5)}$, among others. Furthermore, the calculation of trimmed means may lead to the exclusion of relevant information on the price changes of some goods and services, which could provide some indication on future price developments.

An alternative exists to the allocation of zero weights to items one wishes to exclude and one weights to those not to exclude. This approach consists of attributing variable weights according to the information content of each of the CPI items. Diewert (1995) suggests the attribution of weights that are inversely proportional to price volatility. Laflèche (1997) and Wynne (1997) apply this concept to price behaviour respectively in Canada and the United States of America.

(3) Bryan and Cecchetti (1994) also present a set of economic arguments, based on an application of the model of Ball and Mankiw (1995) where costs of adjustment of prices are taken into account. See for example Bakhshi and Yates (1999).

(4) See for instance Bryan, Cecchetti and Wiggins II (1997), Bakhshi and Yates (1999) and Andrade and O'Brien (1999).

(5) Roger (1997) suggested the utilisation of an asymmetric trimmed measure, which would bring some advantages in terms of efficiency and robustness of the estimator. 


\section{CONDITIONS FOR A CORE INFLATION MEASURE}

This section introduces and discusses necessary conditions for a trend or core inflation measure.

To some extent, this issue has been overlooked in the literature. Sometimes, the potential trend inflation measures are analysed by comparing their behaviour with the trajectory of a so-called "reference measure"(6) for inflation. Coimbra and Neves (1997) use as "reference measure" the median of the CPI's year-on-year change rates, for a 19-month time span, whereas Bryan, Cecchetti and Wiggins II (1997) use a 36-month centred moving average and Bakhshi and Yates (1999) a 37-month centred moving average.

The use of such an approach contains obvious drawbacks. The introduction of these so-called "reference measures" for inflation, on the basis of which the other indicators are evaluated, is never duly justified and so there is no guarantee that these indicators are themselves trend inflation measures with nice properties. Therefore, if it happens that the reference measure is not the best proxy for the (unknown) trend of inflation, then this approach does not guarantee that the best indicator is selected, as the inflation indicator that best approximates the reference measure is not necessarily the one that best approximates the true trend of inflation.

Roger (1997) suggests three properties for a core inflation measure. Ideally this measure should be timely (this would exclude, for instance, symmetric filters like centred moving averages or the Hodrick-Prescott filter), robust and unbiased (otherwise it will provide false signals to economic authorities) and verifiable (to have greater credibility). More recently, Wynne (1999) presented the following six criteria which should be used to select a core inflation measure: 1) to be computable in real time; 2) to be forward-looking in some

(6) See for instance Bryan and Cecchetti (1994), Coimbra and Neves (1997) or Bryan, Cecchetti and Wiggins II (1997). In general, in these papers, a good core inflation indicator is one that minimises the mean square error (MSE) calculated in relation to the "reference measure", i.e. $\sum_{t=1}^{T}\left(\pi_{t}^{*}-\hat{\pi}_{\tau}\right)^{2} / T$, where $\pi_{t}^{*}$ stands for the trend measure, $\hat{\pi}_{t}$ denotes the "reference measure" of inflation and $T$ is the number of observations. sense; 3) to have a track record of inflation of some sort; 4 ) to be understood by the public; 5 ) to be definitive in such that history does not change each time we obtain a new observation; 6 ) to have some theoretical basis, ideally in monetary theory.

There are two main comments that can be made about these conditions. Some of these conditions, however important, have the only purpose of previously excluding some candidate measures and are more a minimum pre-requisite (this is the case, for instance, of the conditions for the indicator to be timely and computable once and for all). Some other conditions, even though important to characterise the measures fulfilling this prerequisite, are defined rather vaguely, and the form of their practical implementation is not addressed (this is the case, for instance, of the requirement for the indicator to provide a robust and unbiased measure of inflation). For this reason, these conditions allow little progress as to characterise the properties of the selected indicators.

To overcome these difficulties, we first introduce a set of a priori conditions that have to be met by any core inflation indicator. Obviously, in the discussion that follows, we implicitly assume that any candidate to be a core inflation measure does meet the pre-requisites of being timely and computable once and for all.

Let us assume that for a given period $t$, the inflation rate, $\pi_{t}$, is broken-down into the sum of two components: a permanent component, named trend inflation - say, $\pi_{t}^{*}$ - and a temporary component of inflation in period $t$, represented by $u_{t}$. Hence, by definition, in each period of time we have:

$$
\pi_{t}=\pi_{t}^{*}+u_{t}
$$

In equation (1) we assume that the temporary disturbances in the inflation rate, $u_{t}$, are caused by events such as changes in weather conditions, disturbances in the demand or supply of some goods, significant adjustments to the prices of some goods for reasons different from those determining the general behaviour of prices, etc. By definition $u_{t}$ is expected to have zero mean and finite variance, for any given moment $t$. Therefore, non-stationarity, understood as the presence of a unit root, is by definition excluded. 
The simple examination of a chart for Portugal, plotting inflation measured by the year-on-year rate of change of the $\mathrm{CPI}$, shows that neither the mean nor the variance of this variable is constant. Therefore, although the issue of the statistical attributes of the inflation rate is in general unsolved, in the Portuguese case it is reasonable to admit that the year-on-year inflation rate has a nonstationary behaviour. More specifically, the statistical tests do not allow to reject the hypothesis of this variable being integrated of order $1^{(7)}$. For this reason, in what follows it is assumed that $\pi_{t}$, the inflation rate, is an integrated process of order 1 , i.e. it is a I(1) variable.

Given the assumption that the inflation rate is a I(1) variable, it then results from equation (1), given the hypotheses on $u_{t}$, that the core inflation measure, $\pi_{\tau}^{*}$, shall also be I(1) and, in addition, must be co-integrated with the observed inflation rate, $\pi_{t}$, so that $z_{t}=\pi_{t}-\beta \pi_{t}^{*}$ is stationary with zero mean for some value of $\beta$.

However, given the hypothesis of a zero mean for $u_{t}$, one should have $\beta=1$, that is to say, $z_{t}=\pi_{t}-\pi_{t}^{*}$ should be a stationary variable with zero mean. It should be noted that if $z_{t}=\pi_{t}-\pi_{t}^{*}$ does not have zero mean, then $\pi_{t}^{*}$ is not capturing all the systematic movements included in $\pi_{t}$, i.e., there is a non vanishing difference between and $\pi_{t}$ and $\pi_{t}^{*}$. Something similar happens if $\beta \neq 1$. Also in this case, $\pi_{t}^{*}$ does not account for all the permanent movements included in $\pi_{t}$. The net result shall correspond to either a faster (if $\beta<1$ ) or slower (if $\beta>1$ ) systematic growth of $\pi_{t}^{*}$ vis-à-vis $\pi_{t}$. The condition that $z_{t}=\pi_{t}-\pi_{t}^{*}$ is a zero-mean stationary variable is, therefore, the first necessary condition for a trend inflation indicator. This condition was initially proposed by Freeman (1998).

We now turn to how to motivate the need for additional conditions. First, the variable $\pi_{t}^{*}$ is to behave as an attractor for $\pi_{t}$, i.e., in the long run, $\pi_{t}$ must converge to $\pi_{t}^{*}$. In fact, if the variable $\pi_{t}^{*}$ does not exhibit this property, its interpretation as a core inflation measure is not useful in any sense. If there is no reason to expect that $\pi_{t}$ will converge to $\pi_{t}^{*}$, there is no point in knowing whether in a given period $\pi_{t}^{*}$ is above or below $\pi_{t}$. However, if $\pi_{t}^{*}$ is an attractor for $\pi_{t}$, we can ensure that if in a given pe-

(7) See for instance Sousa (1996) $\operatorname{riod} \pi_{t}$ is above (below) $\pi_{t}^{*}$, there is a reason to expect that, sooner or later, $\pi_{t}$ will start to decrease (increase) and converge to $\pi_{t}^{*}$. Note that this condition, which we shall consider the second condition, includes as a special case the requirement of Granger causality. In particular, this condition requires that $\pi_{t}^{*}$ Granger causes $\pi_{t}$, i.e., that $\pi_{t}^{*}$ is a leading indicator of the of inflation rate.

Finally, it is important to ensure that the second condition does not occur the other way around, i.e., that $\pi_{t}$ is not an attractor for $\pi_{t}^{*}$ and also that $\pi_{t}^{*}$ is not "too" sensitive to observed outliers in $\pi_{t}$ in the recent past. The need for the first half of this third condition is quite understandable. If $\pi_{t}^{*}$ is itself attracted by the inflation rate, then it will be very difficult to anticipate the most likely future sign of the change in the inflation rate. The fact, for instance, that in a given period $\pi_{t}^{*}$ is above $\pi_{t}$ does not indicate necessarily that it will be $\pi_{t}$ who will converge to $\pi_{t}^{*}$ and not the contrary. The second part of this condition ensures that the trend inflation indicator is insensitive to the presence of outliers in the inflation rate, hence rendering necessarily a smother measure than the inflation rate itself.

Combining the second and the third condition, we can conclude that if in a given period inflation stands above the trend indicator, then under normal circumstances there are reasons to expect that inflation will decrease, thus converging to the trend indicator.

The technical details of the econometric formulation and of the statistical tests for these three conditions can be seen in Marques, Neves and Sarmento (1999).

\section{AN EMPIRICAL ILLUSTRATION: THE CPI IN PORTUGAL IN THE PERIOD 1993-1998}

This section analyses the behaviour of a set of trend inflation measures for the period running from July 1993 up to November 1999. The choice of a relatively short time span is due to two reasons. First, the CPI recorded important re-basing in previous years (1976, 1983 and 1991), which makes it difficult to operate with a relatively consistent classification of the CPI items for a longer period. Second, 1992 saw a significant change of 
VAT rates; hence it would be difficult to analyse this period.

The measures considered in this analysis are the following:

\section{a) Trimmed mean (TM 10 and TM 25)}

The trimmed mean of the year-on-year changes of the CPI is obtained by eliminating a given percentage of the highest and lowest price changes. The Banco de Portugal discloses the 10 per cent trimmed mean on a regular basis ${ }^{(8)}$. This indicator corresponds to the average of the 80 per cent central year-on-year price changes in the CPI. Coimbra and Neves (1997) recommended the utilisation of this indicator, with detriment to alternative indicators, as a result of the application of a set of criteria different from that proposed in the present analysis.

This is a symmetrical trimmed mean, as it excludes the same percentage of outliers at the upper and the lower tails of the distribution. We analyse two kinds of trimmed mean: the 10 per cent trimmed mean (TM10) and the 25 per cent trimmed mean (TM 25).

\section{b) Underlying inflation (UNI)}

The concept of "underlying inflation" used by the Banco de Portugal was originally proposed by Nascimento (1990). In general, this indicator (hereafter referred to as UNI) is obtained from the CPI when excluding non-processed foodstuff goods and energy.

\section{c) First principal component (FPC)}

Coimbra and Neves (1997) proposed the utilisation of the first principal component (FPC) of the year-on-year changes of the CPI as an alternative trend inflation indicator ${ }^{(9)}$. The behaviour of this indicator has been quite regularly referred in the Economic Bulletin of the Banco de Portugal.

The application of the principal components technique can be interpreted as a means of seizing

(8) The Banco de Portugal published the trimmed mean for the first time in the March 1997 Economic Bulletin, in the article "Inflation - prospects for 1997 and 1998". the general trend of prices. Therefore, one is admitting that the price change of each CPI item reflects not only specific factors but also the general behaviour of prices.

\section{d) Weighted standard deviation CPI (SDI)}

Following the suggestion of Diewert (1995) and Wynne (1999), we calculated a price change where in the place of the usual CPI weights we used a measure of the relative volatility of each CPI item in relation to the average change of CPI itself. The formula used was:

where

$$
S D I_{t}=\frac{\sum_{i=1}^{N} w_{i t} P_{i t}}{\sum_{i=1}^{N} w_{i t} P_{i t-12}} \text { with } w_{i t}=\frac{\frac{1}{\sigma_{i t}}}{\sum_{j=1}^{N} \frac{1}{\sigma_{j t}}}
$$

$$
\sigma_{i t}=\sqrt{\frac{\sum_{j=t-m+1}^{t}\left[\left(\pi_{i j}-\pi_{j}\right)-\left(\overline{\pi_{i t}-\pi_{t}}\right)\right]^{2}}{m}} \text { for } i=1,2, \ldots N
$$

with

$$
\left(\overline{\pi_{i t}-\pi_{t}}\right)=\sum_{j=t-m+1}^{t} \frac{\left(\pi_{i j}-\pi_{j}\right)}{m}
$$

where $\pi_{i t}$ is the year-on-year rate of change of the prices of component $\mathrm{I}$ in period $t$ and $\pi_{t}$ stands for the year-on-year rate of change of the original CPI in period $t$.

Charts in the Appendix depict these indicators for the sample period as well as the difference between these indicators and the year-on-year rate of inflation.

For the reasons presented in section 2, the analysis shall lie upon the assumption that the year-on-year inflation rate is an integrated variable of order 1.

To analyse the first condition, we took as the starting point the result of the unit root test - referred to in the literature as the augmented Dickey-Fuller (ADF) test - to the series $\left(\pi_{t}-\pi_{t}^{*}\right)$, where $\pi_{t}$ stands for the year-on-year rate of infla-

(9) A limitation of this indicator derives from the fact that the principal components technique gives rise to a scale-less measure. As a result, it becomes necessary to find a priori an appropriate level for which the indicator can be directly compared with inflation. 
tion and $\pi_{t}^{*}$ denotes the trend inflation indicator. To explain this procedure, recall that the first condition stipulates the existence of co-integration between $\pi_{t}$ and $\pi_{t}^{*}$ with a unit coefficient and zero constant. This means that in the co-integration regression

$$
\pi_{t}=\alpha+\beta \pi_{t}^{*}+u_{t}
$$

residuals are stationary, $\beta=1$ and $\alpha=0$. Equation (2) can be written as follows

$$
\left(\pi_{t}-\pi_{t}^{*}\right)=\alpha+(\beta-1) \pi_{t}^{*}+u_{t}
$$

from which we infer immediately that $\left(\pi_{t}-\pi_{t}^{*}\right)$ is stationary if and only if $u_{t}$ is a stationary variable and $\beta=1$. In the case the hypothesis of the existence of a unit root is rejected for series $\left(\pi_{t}-\pi_{t}^{*}\right)$, them this means that $\pi_{t}$ and $\pi_{t}^{*}$ are co-integrated and $\beta=1$ in (2). In this case the ADF test can be utilised to test the hypothesis of $\alpha=0$, which only requires that the regression constant is analysed.

To test the second and third conditions it is necessary to specify dynamic models for $\pi_{t}$ and $\pi_{t}^{*}(10)$.

Table 1 displays the results of the analysis carried out for the five indicators under scrutiny. We now recover the set of conditions that are being tested:

Condition 1: the difference between observed inflation and the trend indicator must be a zero-mean stationary variable;

Condition 2: the trend inflation indicator must behave like an attractor of the rate of inflation, in the sense that it provides a leading indicator of inflation;

Condition 3: observed inflation should not be an attractor of the trend inflation indicator.

Table 1 shows that three indicators - UNI, FCP and SDI - totally fulfil the first condition. But the trimmed means (whether at 10 or 25 per cent), despite being co-integrated with the rate of inflation and fulfilling condition $\beta=1$, do not comply with condition $\alpha=0$. This means that both indicators are systematically skewed vis-à-vis the rate of inflation, as Coimbra and Neves (1997) had

(10)See Marques, Neves and Sarmento (1999) for further technical details.
Table 1

\section{EVALUATION OF THE CORE INFLATION

\begin{tabular}{|c|c|c|c|c|}
\hline & \multicolumn{2}{|c|}{ First condition } & \multirow{2}{*}{$\begin{array}{l}\text { Second } \\
\text { condition }\end{array}$} & \multirow{2}{*}{$\begin{array}{c}\text { Third } \\
\text { condition }\end{array}$} \\
\hline & $\beta=1$ & $\alpha=0$ & & \\
\hline TM $10 \ldots . .$. & Yes & No & Yes & Yes \\
\hline TM 25...... & Yes & No & Yes & Yes \\
\hline UNI $\ldots \ldots \ldots$ & Yes & Yes & No & No \\
\hline FPC $\ldots \ldots \ldots$ & Yes & Yes & Yes & Yes \\
\hline SDI $\ldots \ldots \ldots$ & Yes & Yes & Yes & Yes \\
\hline
\end{tabular} INDICATORS}

already demonstrated for the Portuguese case (see charts in Appendix).

The bias of the trimmed means has a relatively simple explanation. Indeed, recent researches show that in most cases the distributions of yearon-year price changes are not symmetrical. Instead, they tend to exhibit a predominantly positive degree of asymmetry. As for the Portuguese case, the studies by Coimbra and Neves (1997) showed that the distribution of price changes exhibited relatively lasting periods of positive asymmetry alternating with negative asymmetry. The fact that in Table 1 we obtained $\alpha \neq 0$ indicates in principle that in the period under review the negative and the positive asymmetry periods do not fully offset each other.

As for indicators UNI and SDI, it should be noted that condition $\alpha=0$ is not rejected, but only at the limit - therefore suggesting the existence of some bias in this indicator as well.

The third column in Table 1 shows that all indicators except for underlying inflation verify the second condition. This conclusion is quite robust as it depends neither on the number of lags used in the estimated model nor on whether the model has a constant or not.

The last column in the Table 1 shows that the third condition is also fulfilled by all indicators except underlying inflation, although in this case the conclusion regarding the trimmed mean at 10 per cent is not very robust.

The results of the tests hence confirm the already existing idea that underlying inflation does not provide a good indicator of trend inflation ${ }^{(11)}$. 
This is because, contrary to what would be desirable, this indicator in not a leading indicator. In fact, it works as a lagging indicator of inflation. Indeed, changes in the prices of the goods excluded from the indicator (energy and non-processed food) affect directly and contemporarily the CPI, while only transmitting indirectly and with some lag to underlying inflation, which hence becomes a lagging indicator of inflation.

In brief, one can say that from the five indicators analysed, only two - the first principal component and the SDI - fulfil all conditions. However, as regards trimmed means, it should be noted that only the first condition is unfulfilled, hence these indicators may still be used. In fact, if these indicators were adjusted so as to take into account the skewness of the price changes distribution, they would possibly fulfil all three properties.

\section{CONCLUSIONS}

This paper defines a minimum set of criteria that should be verified by a trend inflation indicator; through appropriate statistical procedures, it also tests if a relatively wide range of trend inflation indicators meet these criteria. The main conclusions are the following:

a) "Underlying inflation" does not provide an appropriate core inflation indicator as it lags the year-on-year rate of inflation; this result is in line with those obtained by other authors, employing alternative statistical procedures;

b) Trimmed means, as currently calculated by the Banco de Portugal, meet in general the criteria proposed in this article; however, in the sample period, these indicators exhibit a lower average price change than that of inflation, which is also in line with the findings of other authors; this result is also due to the fact that the cross-section distribution of year-on-year price changes exhibit relatively lasting periods of asymmetry, which

(11)See for example Coimbra and Neves (1997) and Cecchetti (1997). are alternatively positive and negative and do not fully compensate each other.

c) The "first principal component" indicator fulfils all criteria proposed in this study; it therefore should continue being used as a trend inflation indicator;

d) The indicator obtained through re-weighting the CPI according to the volatility of the prices of its items vis-à-vis inflation, and whose statistical properties are for the first time discussed for the Portuguese case in this article, also meets all criteria; however, it should be noted that there are signs of some bias vis-à-vis the inflation rate.

These findings suggest two guidelines for future research. First, trimmed means require further development as to take into account the skewness of the cross-section distribution of price changes. Second, the SDI indicator deserves a closer analysis that considers alternative forms of obtaining the weights of each CPI item.

\section{REFERENCES}

Andrade, I.C. and R. J. O'Brien (1999), "A Measure of Core Inflation in the UK", mimeo.

Álvarez, L.J. and Ma . de los Llanos Matea (1999), "Underlying Inflation Measures in Spain", Banco de Espanha, Working Paper no. 9911.

Bakhsi, H.; Yates, T., 1999, "To trim or not to trim, An application of a trimmed mean inflation estimator to the United Kingdom", Bank of England, Working Paper Series no. 97.

Ball, L. and N.G. Mankiw (1995), "Relative price changes as aggregate supply shocks", Quarterly Journal of Economics, 110, pp. 161-193.

Bryan, M.F. and S.G. Cecchetti (1993), "The Consumer Price Index as a Measure of Inflation", Economic Review of the Federal Reserve Bank of Cleveland, 1993:4, pp 15-24.

Bryan M. F., Cecchetti S. G., 1994,"Measuring core inflation", in Monetary Policy, edited by $\mathrm{N}$. Gregory Mankiw, University of Chicago Press for NBER, 195-215;

Bryan M. F., Cecchetti S. G., Wiggins II R. L., 1997, "Efficient inflation estimation", NBER, Working Paper no. 6183; 
Cecchetti, S. G. (1997), “Measuring Short-Run Inflation for Central Bankers", Review of the Federal Reserve Bank of St. Louis, Vol. 79, number 3, pp. 143-155.

Coimbra C., Neves P.D., 1997, "Trend inflation indicators", Banco de Portugal, Economic Bulletin, March.

Dias, F. C. and M. R. Pinheiro (1995), "Shocks and inflation", Banco de Portugal, Economic Bulletin, December.

Diewert, W.E. (1995), “On the Stochastic Approach to Index Numbers", Department of Economics, University of British Columbia, Discussion Paper DP59-31.

Engle R., Granger C.W.J., 1987, “Co-integration and error correction: representation, estimation, and testing", Econometrica, Vol.55, no. 2, 251-276;

Fischer, Andreas M., 1989, "Unit roots and survey data" Oxford Bulletin of Economics and Statistics, Vol 51, no. 4.

Freeman, Donald G., 1998, "Do core inflation measures help forecast inflation?", Economics Letters, Vol. 58.

Gartner, C. and G.D. Wehinger (1998), "Core Inflation in Selected European Countries",
Oesterreichische Nationalbank, Working Paper no. 33 .

Laflèche T., 1997, "Statistical measures of the trend rate of inflation", Bank of Canada Review, Autumn;

Marques, C.R., P.D. Neves and L.M. Sarmento (1999), "Evaluating Core Inflation Indicators", Banco de Portugal, mimeo.

Nascimento, T. (1990), "Inflation indicators", Banco de Portugal, Quarterly Bulletin, Vol. 12, no. 4, December.

Quah, D. and S.P. Vahey (1995), "Measuring Core Inflation", Economic Journal, Vol. 105, No 432.

Roger, S., 1997, "A robust measure of core inflation in New Zealand, 1949-96"; Reserve Bank of New Zealand;

Sousa, J., 1996, " A money demand function for Portugal", Banco de Portugal, Working Paper no. 7-96.

Wynne, M. A. (1997), commentary on "Measuring Short-Run Inflation for Central Bankers", Review of the Federal Reserve Bank of St. Louis, Vol. 79, no. 3.

Wynne, M. A., 1999, "Core inflation: a review of some conceptual issues", European Central Bank, Working Paper no. 5; 


\section{COMPARISON BETWEEN THE CPI AND CORE INFLATION INDICATORS}

Chart $1 \mathrm{~A}$

Year-on-year rates of change of the CPI and of the10 per cent trimmed mean

(TM 10)

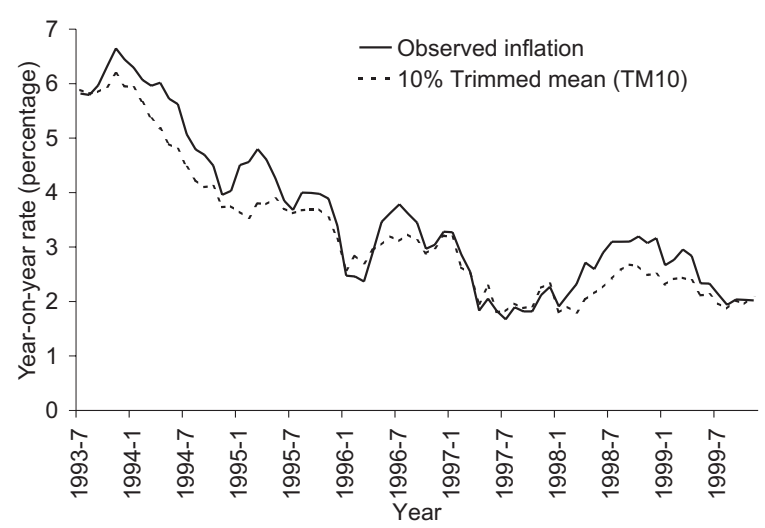

Chart 2A

Year-on-year rates of change of the CPI and of the 25 per cent trimmed mean

(TM 25)

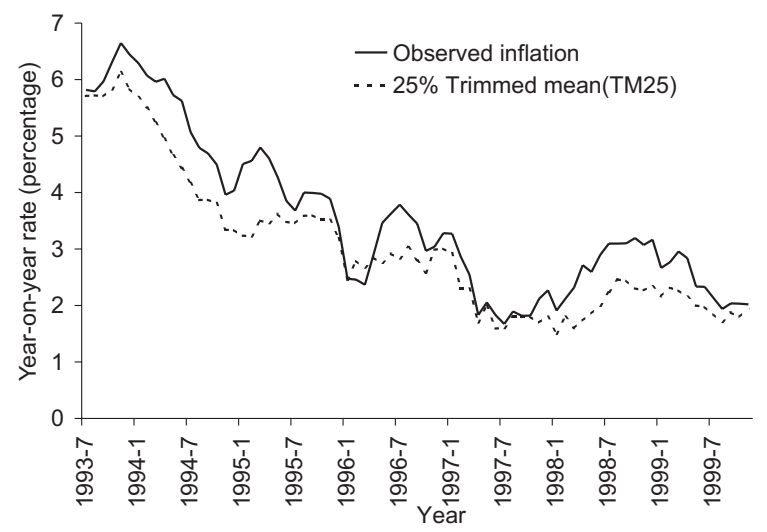

Chart 3A

Year-on-year rates of change

of the CPI and of the first

principal component

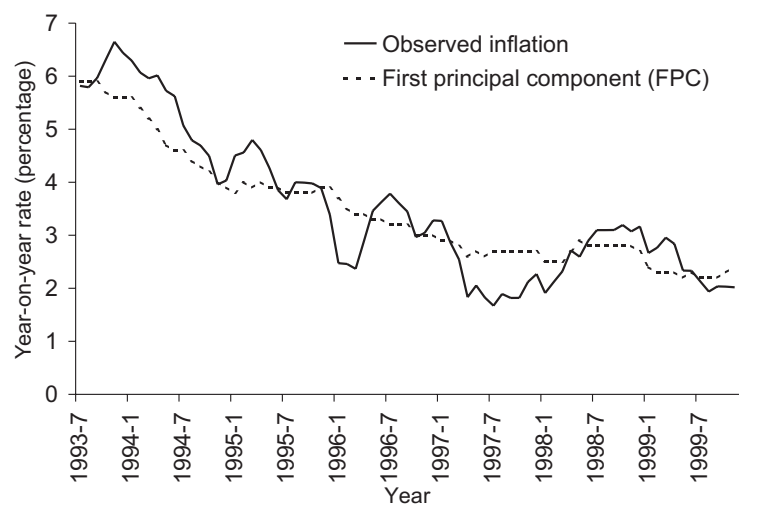

Chart $1 \mathrm{~B}$

Difference between the year-on-year rates of change of the CPI and of the 10 per cent trimmed mean

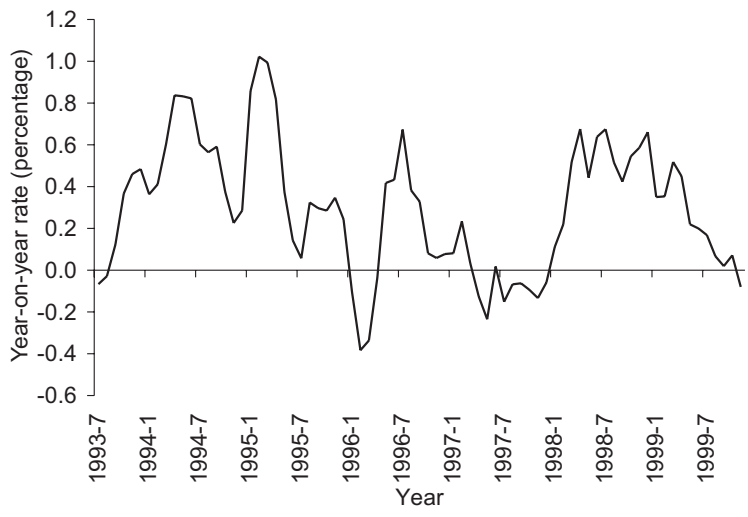

Chart 2B

Difference between the year-on-year rates of change of the CPI and of the 25 per cent trimmed mean

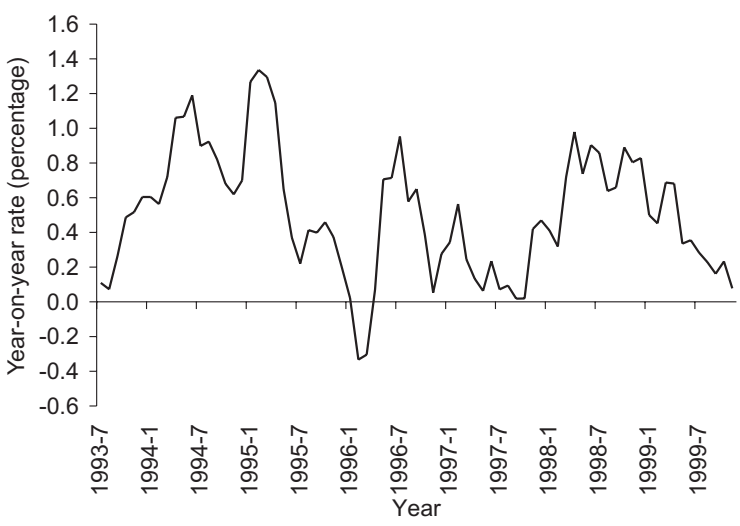

Chart 3B

Difference between the year-on-year rates of change of the CPI and of the first principal component

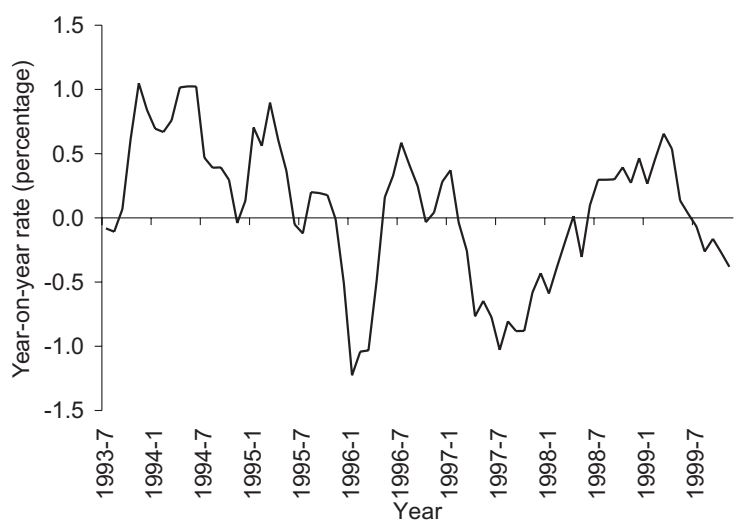




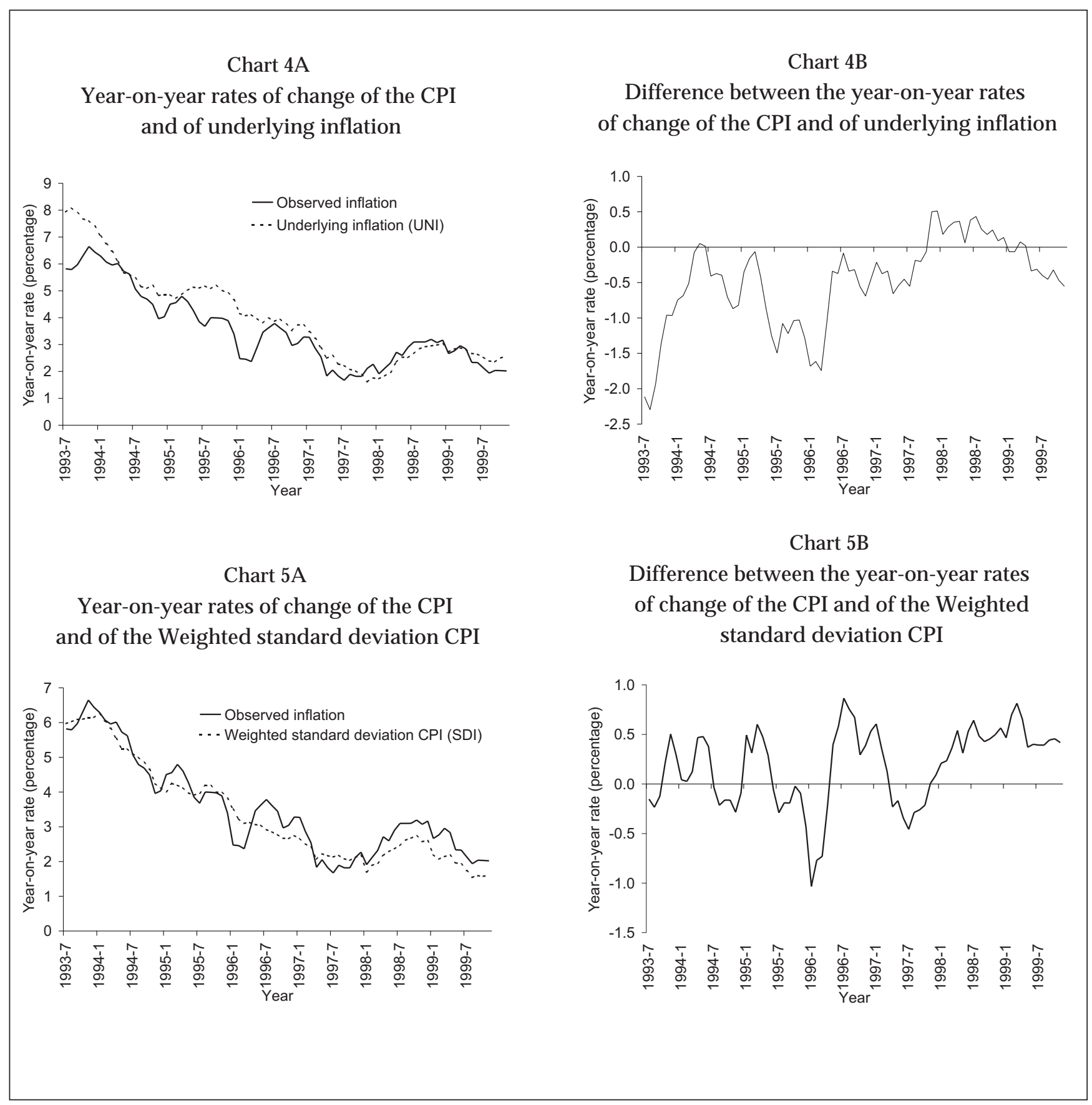

